\title{
The noncontact determination technique research of dangerously loaded zones in the underground mining
}

\author{
Aleksey Bizyaev ${ }^{1}$, Natalia Voronkina $^{2}$, Andrey Savchenko ${ }^{3}$, and Michail $\mathrm{Cupov}^{3}$ \\ ${ }^{1}$ Novosibirsk State Technical University, Russia \\ ${ }^{2}$ Siberian Coal Energy Company, Head of the Department for Control of Dynamic Phenomena and \\ Monitoring of Rock Mass, Russia \\ ${ }^{3}$ Chinakal Institute of Mining SB RAS, Novosibirsk, Russia
}

\begin{abstract}
The electromagnetic radiation signals associated with the destruction of rock samples were studied under field and laboratory conditions. The parameters of the signal were found that preceded the violation of the integrity of the rock in laboratory studies. It is shown that the highest efficiency of the method of electromagnetic radiation is achieved when predicting the dynamic manifestations of rock pressure in the form of rock shock.
\end{abstract}

\section{Introduction}

In the works [1-8] it was shown that the destruction of a rock is accompanied by electromagnetic radiation. The nature of this radiation is not fully understood. The radiation of rock during destruction is used in predicting the dynamic manifestations of rock pressure. In the works [1-4,7-8] it was shown that the discontinuity of the rock is accompanied by an increase in the flow of impulses. The equipment Angel-M, which is used in the mines of JSC SUEK-Kuzbass, is built on this observation. In the works [5-8] the process of destruction of rocks, accompanied by four stages of destruction, is considered. From the first to the third stage, the process is considered as pre-destruction. At the third stage of destruction, a discontinuity of the rock and an avalanche-like destruction are observed. This paper presents a laboratory analysis of the electromagnetic radiation (EMI) signals of the host rock from the S.M. Kirov mine. The results of profiling the mine work site in a place prone to discontinuity are presented. The recommendations for the development of the architecture of the registration and diagnostic complex REMI, which includes software and an electromagnetic radiation recorder with a graphic display, are given. 


\section{Laboratory studies of mining samples}

\subsection{Description of the laboratory stand}

The stand includes a press, an EMP sensor, a load measurement sensor, a displacement sensor, an amplifier system, a recording system, and a system for storing, displaying, and analyzing data. The press consists of two metal plates with dimensions of 300x180x45mm, fixedly mounted on four steel columns with a diameter of $35 \mathrm{~mm}$. Uniaxial loading of the samples was carried out until they were completely destroyed, which was determined by a sharp drop in load.

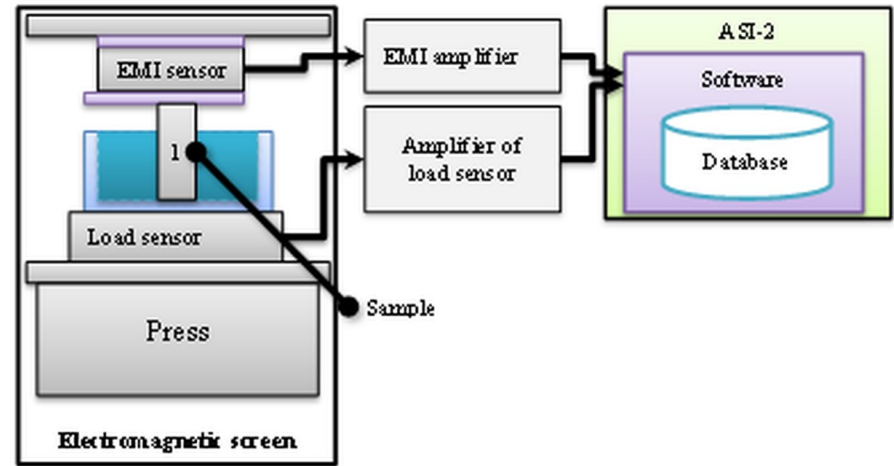

Fig. 1. Structural scheme of the laboratory stand ASI-2.

When testing the host rock mine samples from the S.M. Kirov mine were taken in size $25 \times 25 \times 40 \mathrm{~mm}$, then subjected to uniaxial compression until complete destruction on the ASI-2 laboratory stand. During the destruction, the signals of electromagnetic radiation and loads were synchronously recorded.

\subsection{Description of the laboratory experiment}

During the registration, a synchronous oscillogram of the destruction process was obtained (Fig. 2). Roman numerals show the stages of destruction, obtained according to [8], by the change in the flow of pulses.

From the oscillogram it is seen that in the process of destruction, the sample is not able to accumulate mechanical load and is destroyed when the load is not more than $1 \mathrm{kN}$. The first mechanical load unloading occurred in the interval $15800-20000 \mathrm{~ms}$, with the load corresponding to $3 \mathrm{kN}$. The second failure occurred in the interval $27500-30000 \mathrm{~ms}$, with the accumulation of load. 


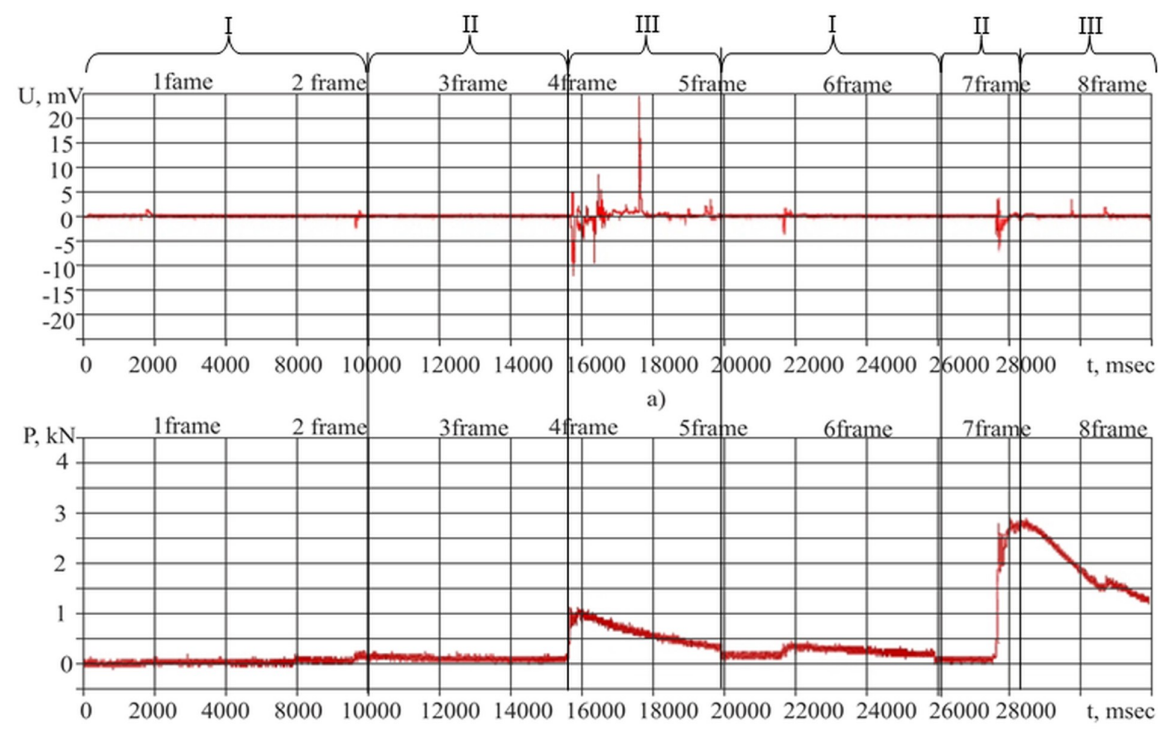

Fig. 2. EMI (a) and loads (b) waveforms recorded during the destruction of a rock specimen.

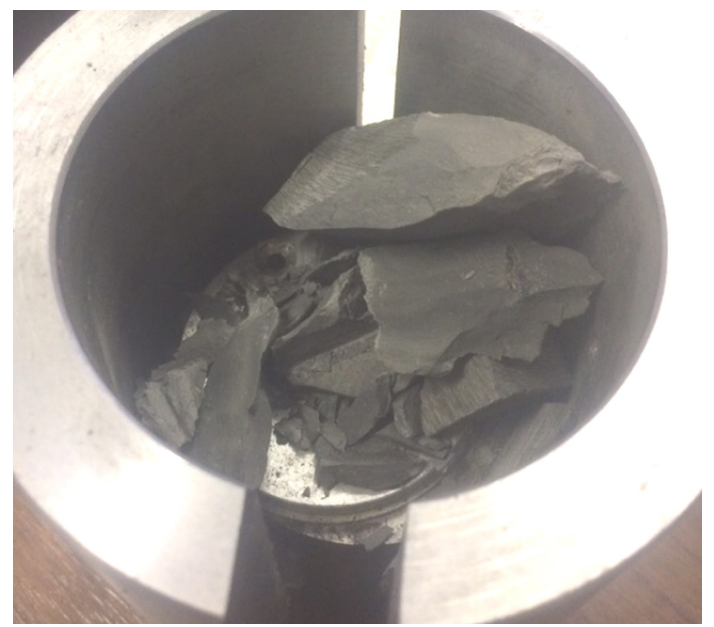

Fig.3. Fragments of a destroyed host rock specimen.

From fig. 2-3 it can be seen that the rock is not able to accumulate mechanical stresses and collapses under load of no more than $5 \mathrm{kN}$. Breed crumbles with minor loads. This shows that in an array with such a rock, the stress-strain state will manifest itself in the form of desquamation, which is observed in the S.M. Kirov mine. However, if such a peeling is manifested in the mine cavity or not timely implementation of preventive measures to replace the lining can lead to significant collapses. 


\section{Natural Studies}

\subsection{Description of the equipment}

Field studies were carried out using the Angel-M mine equipment [10] and the REMI-3 registration and diagnostic complex [4].

Mine automated complex "Angel-M" is presented in Fig. 4 and consists of a registration unit with an indicator, an electromagnetic radiation sensor, and a data reception program [10].

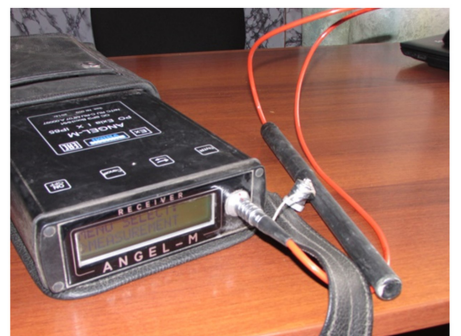

a)

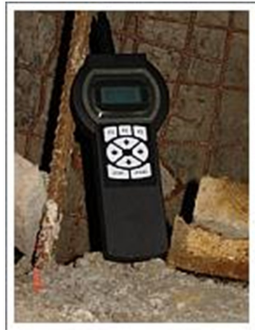

b)

Fig. 4. Detector of Electromagnetic Radiation Angel-M (a) and REMI-3 (b).

Monitoring of the electromagnetic environment is carried out in four stages: reception and selection of signals from the sensor during a specified time interval; data processing with determining the number of amplitude components that exceed threshold values per unit time; comparison of the obtained distribution of amplitude components with standards (criteria for assigning a control area to a certain category); displaying the category score on the display and storing the results in non-volatile memory.

REMI-3 recorder is capable of registering a signal at a frequency of $100-500 \mathrm{kHz}$, with a sampling frequency of $1 \mathrm{MHz}$. Registration results are recorded in non-volatile memory.

\subsection{Taking measurements}

The mine of S. M. Kirov, JSC SUEK-KUZBASS, located in city Leninsk-Kuznetsk, Kemerovo region, was chosen as the place of research. The methane mine category is a super category. Work on identifying hazardous areas was carried out in productive strata: the Boldyrevsky stratum - power is $1.8-2.4 \mathrm{~m}$, the bedding angle is from 0 to $10^{\circ}$; Polenovsky stratum - power is $1.4-1.8 \mathrm{~m}$, the bedding angle is from 0 to $12^{\circ}$. The absolute gas content of the mine is $181.7 \mathrm{~m}^{3} / \mathrm{min}$. The mine has two lava coal mining, four tunneling face. Studies were conducted in the lava 25-101, tunneling slab CMPH 25-03, capital workings, ventilation furnace 25-97 in the zone of geological disturbance and the influence of lava 25-101. To assess the impact of interference from equipment and cables, measurements were made, including in close proximity to areas with a cable network, substations, and mechanisms. The production at various sites was profiled and the comparative characteristics of the registration and diagnostic complex "REMI-3" and "Angel-M" were given.

During the measurements, signals were jointly recorded by the REMI-3 and Angel-M instruments. The measurement results of the device REMI-3 with the integration in the interval of $1 \mathrm{~ms}$ were recorded, and the signal component in the interval of 15 seconds was recorded in the memory. Oscillograms at various sites of mine workings are shown in fig. 5 and Fig. 6. The readings of the Angel-M instrument were recorded simultaneously, the 
readings of which were recorded in the form of two parameters. The measurement results are shown in table 1 .

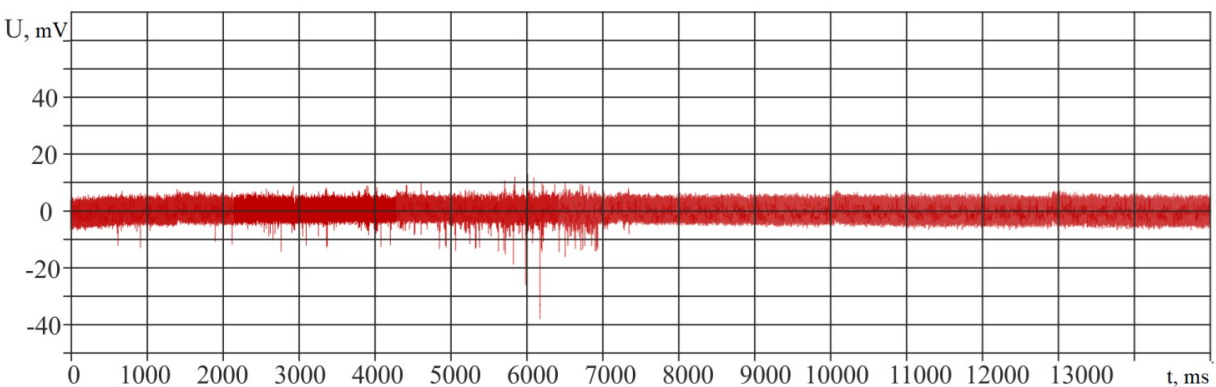

Fig. 5. The results of measurements of the EMP level at PK72

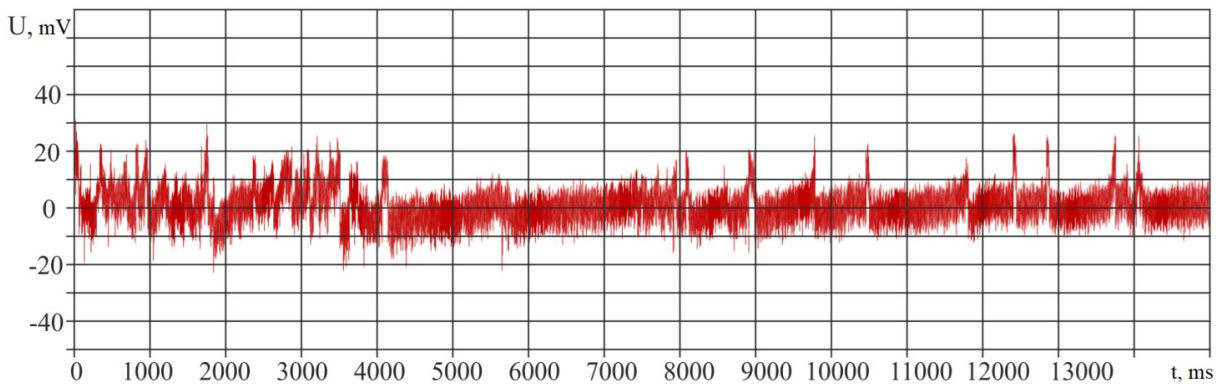

Fig. 6. The results of measurements near the lava 50 meters from KSH.

Table 1. Results of measurements with the device REMI-3 and Angel-M.

\begin{tabular}{|l|c|c|}
\hline \multicolumn{1}{|c|}{ Location } & "Angel-M" & "REMI-3" \\
\hline \multirow{2}{*}{ Conjugation with BIS } & $\mathrm{A}=08,5 \mathrm{~B}=0,143$ & $0-150$ \\
2503 and CMPH & $\mathrm{A}=25,5 \mathrm{~B}=0,173$ & $50-300$ \\
& $\mathrm{~A}=10,8 \mathrm{~B}=0,128$ & $0-150$ \\
\hline \multirow{3}{*}{ Fault 24 FPO 2503 } & $\mathrm{A}=4,2 \quad \mathrm{~B}=0,278$ & $50-160$ \\
& $\mathrm{~A}=4,4 \quad \mathrm{~B}=0,279$ & $20-150$ \\
& $\mathrm{~A}=4,6 \quad \mathrm{~B}=0,251$ & $20-180$ \\
\hline \multirow{3}{*}{ PK 20 VH Lava } & $\mathrm{A}=4,1 \quad \mathrm{~B}=0,281$ & $15-400$ \\
& $\mathrm{~A}=4,3 \quad \mathrm{~B}=0,288$ & $40-350$ \\
PK52 & $\mathrm{A}=4,1 \quad \mathrm{~B}=0,286$ & $40-150$ \\
& $\mathrm{~A}=4,8 \quad \mathrm{~B}=0,294$ & $70-180$ \\
& $\mathrm{~A}=11, \mathrm{~B}=0,336$ & $10-120$ \\
Conjugation with lava & $\mathrm{A}=8,6 \quad \mathrm{~B}=0,308$ & $50-140$ \\
\hline \multirow{3}{*}{ Lav101 50} & $\mathrm{~A}=15,9 \quad \mathrm{~B}=0,200$ & $200-500$ \\
& $\mathrm{~A}=15,4 \quad \mathrm{~B}=0,366$ & $230-300$ \\
& $\mathrm{~A}=12,0 \quad \mathrm{~B}=0,242$ & $330-400$ \\
\hline \multirow{3}{*}{ Conjugation with KH } & $\mathrm{A}=309,7 \quad \mathrm{~B}=0,026$ & $350-600$ \\
& $\mathrm{~A}=641,4 \quad \mathrm{~B}=0,008$ & $400-750$ \\
& $\mathrm{~A}=292,5 \quad \mathrm{~B}=0,05$ & $360-630$ \\
\hline CMPH 2503 & $\mathrm{A}=50,0 \quad \mathrm{~B}=0,079$ & $30-70$ \\
& $\mathrm{~A}=38,4 \quad \mathrm{~B}=0,097$ & $40-80$ \\
& $\mathrm{~A}=2,8 \quad \mathrm{~B}=0,127$ & $40-80$ \\
\hline & $\mathrm{A}=4,5 \quad \mathrm{~B}=0,291$ & $30-60$ \\
& $\mathrm{~A}=4,1 \quad \mathrm{~B}=0,286$ & $60-90$ \\
& $\mathrm{~A}=4,3 \quad \mathrm{~B}=0,288$ & $80-100$ \\
\hline
\end{tabular}


The measurement results show that measurements with the device REMI-3 and Angel$\mathrm{M}$ correlate with a correlation coefficient of 0.73 . From the oscillograms recorded by the device REMI-3 it can be seen that in those places where there is increased cracking and collapse, the period of single pulses increases from $5 \mathrm{~ms}$ to 100 or more. In places where abundant desquamation is observed, the signal amplitude increases from $5 \mathrm{mV}$ to $20 \mathrm{mV}$, directly near the source.

In the process of profiling the mine workings with the Angel-M and REMI-3 devices, the pickets were selected on an interval of 50 meters (Fig.7).

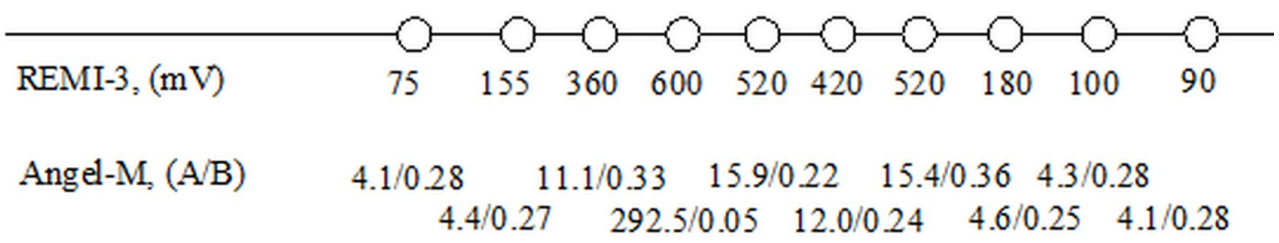

Fig. 7. Measurement results when profiling mine workings at the site of interfacing with lava.

An area was found in which an excess of the background component was observed more than 10 times, at this point the Angel-M device showed the value of the parameter $\mathrm{A}=$ 292.5 , and $B=0.05$. During the measurements, a dynamic manifestation of rock pressure in the form of shooting occurred, after which the instrument values approached the background.

\section{Conclusions}

1. Conducted laboratory studies of the enclosing rock from the Kirov mine. It is shown that the rock is not able to hold the load, there are dynamic manifestations of rock pressure in the form of desquamation.

2. Conducted field studies of the mine working area, with the help of equipment Angel$\mathrm{M}$ and REMI-3. It is shown that on the site, the most significant from the point of view of forecasting are oscillograms, which show the nature of the boards in contrast to the averaged parameters.

3. In places with a probable manifestation of rock pressure, an excess of the background component is observed by more than 10 times.

\section{References}

1. G.E. Yakovickaya, Physical problems of the destruction of rocks, 1, 98-103 (2003)

2. M.V. Kurlenya, G.I. Kulakov, G. E. Yakovitskaya, Fiziko-tekhnicheskie problemy razrabotki poleznykh iskopaemykh, 1, 12-21 (1991)

3. V.S. Kuksenko, I.Ye. Inzhevatkin, B.C. Manzhikov, Fiziko-tekhnicheskie problemy razrabotki poleznykh iskopaemykh, 1, 9-22 (1987)

4. A. G. Vostretsov, G. E. Yakovickaya, A. A. Bizyaev, Reports of the Academy of Higher Education of the Russian Federation, 3:28, 29-38 (2015)

5. A.G. Vostretcov, A.A. Bizyaev, Fiziko-tekhnicheskie problemy razrabotki poleznykh iskopaemykh, 6, 204-210 (2017)

6. A.G. Vostrtcov, G.E. Yakovickaya, A.A. Bizyaev, Reports of the Academy of Higher Education of the Russian Federation, 3:40, 38-48 (2018) 
7. A.G. Vostretcov, G.E. Yakovickaya, A.A. Bizyaev, Reports of the USSR Academy of Sciences, 2:21, 46-54 (2013)

8. A.A. Vorobiev, E.K. Zavodovskaya, V.N. Salnikov, Reports of the USSR Academy of Sciences, 220:1, 82-85 (1975)

9. A.G. Vostretcov, A.A. Bizyaev, Scientific Bulletin of the Novosibirsk State Technical University, 3:32, 37-44 (2008)

10. D.V. Yakovlev, S.N. Mulev, Coal, 10, 14-19 (2014) 